\title{
"Por la justicia de su causa que Dios defiende": José de San Martín y la liturgia republicana
}

\author{
Carlos Piccone Camere \\ Universidad de Londres
}

Los serenos siempre que al anunciar la hora digan el Ave María, añadirán: ;Viva la Patria! ${ }^{1}$

El 28 de julio de 1821, don José de San Martín pronunció a viva voz una alocución memorable cuyo eco no ha dejado de resonar en las efemérides anuales de la independencia para avivar el patriotismo peruano. El Libertador, a través de una sentida proclama, invitó a vitorear a la patria, a la libertad y a la independencia, en medio de una liturgia escrupulosamente maquinada -sustancialmente civil, pero con visos religiosos-, en la que el tañer de las campanas se fundía con los cañonazos de las fuerzas independentistas. Dentro de ese ritual, el nombre de Dios apareció como la pieza de engranaje que ponía en movimiento el anhelo emancipador, lo sostenía, lo dilataba y lo justificaba:

Y acallado el alborozo del inmenso concurso, [San Martín] pronunció estas palabras que permanecerán esculpidas en el corazón de todo peruano eternamente: “El Perú es desde este momento libre e independiente por la voluntad general de los pueblos, y por la justicia de su causa que Dios defiende". Batiendo después el pendón y en el tono de un corazón anegado en el placer puro y celestial que solo puede sentir un ser benéfico, repetía muchas veces: "Viva la Patria. Viva la Libertad. Viva la Independencia"; expresiones que como eco festivo resonaron en toda la plaza, entre el estrépito de los cañones, el repique de todas las campanas de la ciudad, y las efusiones de alborozo universal. ${ }^{2}$

\footnotetext{
1 José de la Riva AgüEro, Decreto sobre policía [Lima, 12 de agosto de 1821], en: Colección de leyes y decretos sancionados desde la jura de la independencia, Tomo 1, Lima, Imprenta del Estado por J. Gonzales, 1825, p. 12.

2 Es la crónica que se recoge en la Gaceta del Gobierno de Lima independiente (tomos del I al III, julio 1821-diciembre 1822). Puede consultarse en la edición realizada en Argentina por el Ministerio de Educación y la Universidad Nacional de La Plata, en ocasión del centenario de la muerte del libertador general San Martín [prólogo de Julio Miguel Laffitte]: Buenos Aires, 1950, pp. 23-24. Véase también: Gamio Palacio, Fernando, La municipalidad de Lima y la emancipación:
}

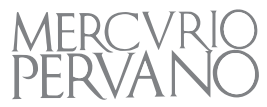


La apelación a la divinidad en un discurso militar tenía, evidentemente, una motivación política más que teológica. ${ }^{3}$ No obstante, compendia bien una serie de cuestiones historiográficas dignas de análisis. En efecto, desde un lado y otro, las partes contenciosas recurrieron a la voluntad y condescendencia divinas para justificar sus propias 'causas', secundadas por empresas bélicas: Dios fue invocado tanto por San Martín como por La Serna, el último virrey del Perú. ${ }^{4}$ El caso del virreinato peruano resulta paradigmático, pues este representaba el centro neurálgico de la dominación española remanente en el continente americano. ${ }^{5}$ Tanto los realistas como los independentistas 'enlistaban' a Dios entre sus tropas para proclamarlo caudillo de sus propias huestes. Incluso el clero se encontraba dividido, pues defendía o atacaba una u otra causa, a través de la difusión de escritos en favor o en contra de la independencia. ${ }^{6}$ No obstante, después de la independencia peruana, el 'factor divino' pareció definirse por un rumbo muy diverso, pues tomaba distancia de ambos partidos, en la medida en que se iniciaba un proceso creciente de romanización eclesiológica, en tanto y en cuanto se empezaba a poner en práctica una teología política según

1821, Lima, Concejo Provincial de Lima y Comisión Municipal del Sesquicentenario de la Independencia Nacional, 1971, p. 74). La Gaceta varió muchas veces de nombre: Gaceta del Gobierno de Lima Independiente (16 julio-5 setiembre, 1821); Gaceta del Gobierno (8 setiembre 18215 abril, 1823); Gaceta del Gobierno de Lima (5-7 abril, 1823); Gaceta del Gobierno (9 abril 1823-30 junio, 1825), Gaceta del Gobierno de Lima (3 julio 1825-29 diciembre, 1825); Gaceta del Gobierno (4 enero 1826-10 mayo, 1826).

3 Gustavo Pons Muzzo, ¿Con qué palabras proclamó San Martín la independencia del Perú?, Documenta: Revista de la Sociedad Peruana de Historia, n. ${ }^{\circ}$ 4, 1965, pp. 382-390. Pons hace una erudita comparación entre tres versiones de las palabras de la proclamación, pero en cualquier caso las tres hacen la misma alocución a la divinidad y señala la empleada en el presente estudio como la más fidedigna. En cambio, Durand parece tomar como fuente a R. Vargas Ugarte y cambia ligeramente el orden de las palabras. Ver Luis Durand Flórez, Compendio histórico del Perú, t. V: La independencia (1780-1824); La República (1826-1899), Lima, Editorial Milla Batres, $1998^{2}$, p. 81.

4 En las postrimerías de la resistencia española, La Serna conmina a Pedro Antonio de Olañeta, su mariscal de campo, con estas palabras: "Espero que V. S. me conteste sencilla y claramente; pues de cuantos perjuicios y males puedan resultar por no proceder V. S. como las leyes de la razón y la tranquilidad pública exigen, será responsable a Dios, a la Nación y al Rey. Dios guarde a V.S. muchos años". Lo cita el conde de Torata [Fernando Valdez y Héctor, comp.], Documentos para la historia de la guerra separatista del Perú; vol. IV: Refutación que hace el Mariscal de Campo Don Jerónimo de Valdés del Manifiesto que el Teniente General Don Joaquín de la Pezuela imprimió en 1821 a su regreso del Perú. Madrid, Imprenta de la Viuda de M. Minuesa de los Ríos, 1895, p. 501).

5 Cf. Heraclio Bonilla y Karen Spalding, La independencia en el Perú: las palabras y los hechos, en: José Matos Mar [dir.], La independencia en el Perú, Lima, Instituto de Estudios Peruanos, 1972, p. 30 [pp. 15-64].

6 Cf. Ruth A. Hill, Literary absolutism: "Fable" and "history" in Spain and Peru (1670-1900) [Volumes I and II], Michigan, University of Michigan [Dissertation for the Degree of Doctor of Philosophy], 1994, p. 760. Véase también María Claudia Huerta Vera, La cultura del impreso en la guerra de la independencia peruana, 1820-1824, Lima, PUCP [tesis para optar por el título de Licenciada en Historia], 2017, pp. 61-62. 
las directrices emanadas desde Roma. ${ }^{7}$ Así, pues, si bien en la historia de la independencia americana se constata una invocación constante del nombre de Dios para defender "la justicia de la causa" de un determinado sistema político y social, gracias a la abundancia de fuentes disponibles desde una y otra perspectiva el caso peruano es, en términos historiográficos, uno de los más complejos e inquietantes.

Para contextualizar la proclamación de la independencia peruana -y, en general, las guerras por las independencias nacionales en América- es preciso tener presente el enfrentamiento entre dos corrientes ideológicas partidistas: la de los conservadores y la de los liberales, representadas por la facción realista y la independentista, correspondientemente. ${ }^{8}$ La realidad, sin embargo, es siempre más compleja. ${ }^{9}$ En efecto, desde una perspectiva histórica, se debe además considerar el recambio dinástico acaecido en la Corona española a inicios del siglo XVIII, con la asunción al trono de los borbones, que relevaron a sus pares de la casa de Habsburgo. ${ }^{10}$

Se sabe que las reformas borbónicas aplicadas en América exacerbaron los ánimos de los americanos, ${ }_{1}^{11} \mathrm{e}$ impactaron especialmente en los grupos étnicos

7 Al respecto véase más detalladamente: Rolando IBERICo RuIz, "La fe de todos los siglos":
una aproximación a la relación entre teología ultramontana e historiografía católica en
el Perú", Revista Cultura y Religión, vol. 9, n. ${ }^{\circ} 1,2015$, pp. 9-33. La eclesiología del periodo
preindependiente en el continente americano no estuvo exenta de matices jansenistas y
regalistas. Ver Josep-Ignasi SARANYANA [dir], Carmen José AlEjOs GRAu [coord.], Teología en
América Latina, vol. II/1: Escolástica barroca, ilustración y preparación de la independencia (1665-
1810). Madrid, Iberoamericana-Vervuert, 2005, pp. 33-34. A raíz de las proclamaciones de las
independencias de las naciones americanas, los matices fueron cubiertos por una sólida capa
ultramontana. 8 Cf. Ruth A. Hill, Literary absolutism: "Fable" and "history" in Spain and Peru (1670-1900) [Volumes I and II], Michigan, University of Michigan [Dissertation for the Degree of Doctor of Philosophy], 1994, p. 465.

9 B. Anderson enriquece el debate sobre las independencias americanas, a través de la problematización del análisis tradicional desde enfoques disruptivos, sumamente interesantes. El autor citado sostiene que las potenciales revueltas e insurrecciones de las clases bajas (indígenas y afroamericanos) habrían sido el verdadero detonante independentista que movilizó a la clase criolla, dentro de la cual tuvieron un protagonismo particular los funcionarios e impresores. Cf. Benedict Anderson, Imagined Communities: Reflections on the Origins and Spread of Nationalism. Londres, Verso, 2006, p. 65.

10 Cf. John A. Crow, Spain: The Root and the Flower: An Interpretation of Spain and the Spanish People. Berkeley, University of California Press, $1985^{3}$, p. 228.

11 Cf. John Robert Fisher, Bourbon Peru, 1750-1824. Liverpool, Liverpool University Press, 2003, p. 104. Véase también Claudia Rosas Lauro, El miedo a la revolución. Rumores y temores desatados por la Revolución francesa en el Perú, 1790-1800, en: Claudia Rosas Lauro, El miedo en el Perú: siglos XVI al XX. Lima, Fondo Editorial de la Pontificia Universidad Católica del Perú, 2005, p. 155 [pp. 139-166]. Sobre las reformas borbónicas y su impacto en el Perú, se sugiere revisar la colección de 15 textos que analizan esa cuestión interdisciplinariamente (enfoque histórico-social, educativo y económico: Scarlett O’Phelan Godoy (comp.), El Perú en el siglo XVIII. La Era Borbónica. Lima, Pontificia Universidad Católica del Perú-Instituto Riva-Aguüero, 1999.

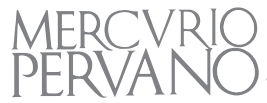


más vulnerables a los nuevos aires político-administrativos. Esa desazón -que desencadenaría la rebelión de Túpac Amaru II- reactivó anhelos revolucionarios en un proceso sin éxito asegurado, pero dentro del cual era posible vislumbrar algunos puntos débiles del sistema del gobierno diseñado en la Península. ${ }^{12}$ Por otra parte, no menos significativa fue la caída del Ancien Régime, que originó la aparición de nuevos protagonistas en la escena política y social de una Francia bullente, ansiosa de extender la revolución más allá de sus fronteras:

El pueblo español, sin embargo, no quería la revolución, y la agresión francesa provocó una de las campañas de apoyo al ejército más espontáneas de la historia del país. Los sacerdotes la promovieron desde sus púlpitos. El gobierno recibió un alud de donaciones. Los voluntarios se presentaron más rápido de lo que el ejército podía armarlos. La tradicional pasión del pueblo español por su religión y su monarquía se reafirmó y los españoles rechazaron la revolución con un fervor que no tardó en verse reflejado en el avance de sus fuerzas armadas. Para sorpresa de los revolucionarios, un ejército español dirigido por el general Antonio Ricardos invadió en abril el Rosellón, en el sureste de Francia, un éxito prematuro sin duda, pero durante el resto de 1793 el ejército francés de los Pirineos tuvo que dedicarse a repeler la invasión española. Entre los invasores se encontraba San Martín [...]. Se trataba de una guerra por Dios, el rey y la patria, pero la Iglesia era incapaz, el rey poco estimulante y el país vulnerable. ${ }^{13}$

A la postre, en las llamadas abdicaciones de Bayona (1808), los reyes Carlos IV y Fernando VII renunciaron, sucesivamente, al trono español a instancias de Napoleón. De esta manera, aunque por poco tiempo, los borbones fueron sustituidos por los Bonaparte, quienes se encontraron de la noche a la mañana "con los derechos sucesorios de una monarquía con extensas posesiones en Ultramar, sobre todo en América". ${ }^{14}$ Esto, evidentemente, tuvo también una resonancia directa en los dominios americanos de la Corona española:

\footnotetext{
12 Sobre la figura de José Gabriel Condorcanqui, cabe añadir que este se convirtió en hito de una historiografía dividida entre aquellos que sostienen que Túpac Amaru II fue, paradójicamente, un agente de la procrastinación de la independencia peruana: Heraclio Bonilla y Karen Spalding, por ejemplo. Ver también Charles WaLKer, The Tupac Amaru Rebellion. Cambridge, The Belknap Press of Harvard University Press, 2014, p. 272. Y, como contraparte, aquellos que han utilizado su figura como un prócer de la independencia nacional, como sucedió durante el gobierno de Juan Velasco Alvarado (1968-1975), al manipularse su significado emblemático, y pretender legitimar el régimen dictatorial. Véase Daniel M. Masterson, Militarism and politics in Latin America. Peru from Sánchez Cerro to Sendero Luminoso. Westport, Greenwood Press, 1991, p. 263.

13 John Lynch, San Martín, soldado argentino, héroe americano. Barcelona, Crítica, 2009, p. 32. Vemos que, en 1793, asoma en la historia la figura de un jovencísimo José de San Martín, combatiendo bajo la enseña española contra los revolucionarios franceses. Casi treinta años más tarde, combatiría contra el ejército realista español en favor de la causa libertadora.

14 Josep Juan Vidal y Enrique Martínez Ruiz, Política interior y exterior de los Borbones. Madrid, Istmo, 2001, p. 393.
} 
La invasión de Napoleón Bonaparte a Europa (1769-1821), en su intento por deponer a los monarcas para establecer su propio imperio, tuvo el efecto de empujar a América Latina hacia la independencia de España. La invasión napoleónica de España y Portugal en 1807 menoscabó la autoridad ibérica en las colonias, detonando posteriormente las guerras de independencia. ${ }^{15}$

A este ambiente de efervescencia política en Europa y de sus consiguientes confrontaciones ideológicas se debe sumar la propia situación de los hombres y las mujeres del continente americano, especialmente de los criollos con acceso a la educación, que, directa o indirectamente, se nutrían de la filosofía francesa y del liberalismo inglés ${ }^{16}$, y avivaban sus esperanzas ante el desenlace exitoso de la gesta independentista de los Estados Unidos ${ }^{17}$ y lo que podría significar para el statu quo de América la Constitución de Cádiz (1812). ${ }^{18}$ Esta élite criolla y mestiza -conformada mayoritariamente por miembros del clero, funcionarios civiles y hombres con formación universitaria, especialmente abogados y médicos- creyó que, para salir de la crisis política, económica y social en la que estaba sumido el virreinato, se hacía necesaria una ruptura definitiva con la madre patria. ${ }^{19}$ El vendaval ideológico europeo cundía en América, pero en el Perú el virrey Abascal -quien se aferraba al poder con políticas absolutistas- era lo suficientemente enérgico y astuto como para desafiar la anacronía de querer seguir haciendo del virreinato peruano una extensión realista.

En este contexto, las palabras célebres pronunciadas por el general José de San Martín al proclamar la independencia del Perú adquieren un particular interés. No obstante, es preciso mencionar que, aunque con resonancias aún limitadas, la declaración de la independencia del Perú ya se había "proclamado" fuera de la capital. ${ }^{20}$ Asimismo, la empresa independentista pudo encontrar un

15 Teresa A. Meade, A history of modern Latin America. 1800 to the present. Chichester, WileyBlackwell, $2016^{2}$, p. 51.

16 Cf. Rosa del Carmen Bruno-Jofré, “La introducción del sistema lancasteriano en el Perú: liberalismo, masonería y libertad religiosa", en Jean-Pierre Bastian [coord.], Protestantes, liberales y francmasones: sociedades de ideas y modernidad en América Latina, siglo XIX. Madrid, Fondo de Cultura Económica, 1990, p. 85 [pp. 84-96].

17 Cf. James Sanders, The Vanguard of the Atlantic World: Creating Modernity, Nation, and Democracy in Nineteenth-Century Latin America. Durham, Duke University, 2014, p. 6.

18 Cf. Elías José Palti, ¿Las ideas fuera de lugar? Estudios y debates en torno a la historia político-intelectual latinoamericana. Ciudad Autónoma de Buenos Aires, Prometeo Libros, 2014, p. 25. Véase también Alberto Ramos Santana, “La Constitución de 1812 y los americanos: de la representación a la emancipación", en Izaskun Álvarez CuARTERO y Julio SÁnchez Gómez [eds.], Visiones y revisiones de la independencia americana: La independencia de América, la Constitución de Cádiz y las Constituciones iberoamericanas. Salamanca, Universidad de Salamanca, 2007, pp. 87-108.

19 Cf. José Agustín de la Puente Candamo, La independencia del Perú. Lima, Fondo Editorial del Congreso de la República del Perú, 2013, p. 116.

20 Así lo demuestran los casos de Piura y Trujillo, por ejemplo (cf. Elizabeth Hernández García, La élite piurana y la independencia del Perú: la lucha por la continuidad en la naciente

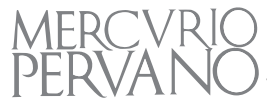


derrotero seguro solo a partir de 1824, en virtud de las campañas de Junín (6 de agosto) y de Ayacucho (9 de diciembre). ${ }^{21}$

Dicho de otro modo, la fecha de la proclamación de la independencia del Perú fue funcional a la causa independentista; esta adquirió una mayor carga simbólica al ser pronunciada por el Libertador don José de San Martín en la capital del virreinato peruano. Al respecto, P. Ortemberg ha planteado que en las primeras horas de la independencia peruana se dio una ritualización -a través de una especie de liturgia civil- por parte de los independentistas: "La proclamación del sábado 28 de julio fue un importante teatro que San Martín juzgó imprescindible para sellar su alianza con la élite limeña, legitimar la independencia y ganar adeptos al bando patriota". ${ }^{22}$ Con más de cien años de distancia, la misma impresión la había manifestado primeramente B. Mitre con términos similares: "La proclamación y jura de la independencia peruana fue otra formalidad, pero no por eso menos memorable". ${ }^{23}$ Sin hacerlo explícito, ambos autores señalan un elemento que se remite, en realidad, más que a una reminiscencia de la coronación y entronización de los soberanos del antiguo régimen, a la tradición veterotestamentaria del binomio inseparable elecciónunción de los reyes de Israel. ${ }^{24}$ De hecho, a través de un imaginario sostenido a través del tiempo, la proclamación de la independencia peruana en 1821 ha sido y sigue siendo considerada, por antonomasia, como el nacimiento de la

república (1750-1824), Lima, Instituto Riva Agüero-Pontificia Universidad Católica del Perú, 2008, p. 303). Véase también Víctor Andrés Belaunde, La constitución inicial del Perú ante el derecho internacional, Lima, Fondo Editorial UNMSM, 1997³, pp. 2-9.

21 Cf. Eugenio Chang-Rodríguez, Latinoamérica: su civilización y su cultura. Boston, Thomson Heinle, $2008^{4}$, p. 114. El 9 de diciembre de 1824, desenlace de la batalla de Ayacucho (junto con lo que supuso el histórico 12 de octubre de 1492), fue, según P. Grases, y en la línea de A. Uslar Pietri, la fecha clave en la historia americana, pues con ella se "liquidó definitivamente el dominio español desde México hasta los confines de Magallanes". Pedro Grases, Escritos selectos. Caracas, Biblioteca Ayacucho, 1989, p. 196.

Tómese en cuenta, sin embargo, la bibliografía que ha renovado la perspectiva social de la historiografía americana tradicional/oficial, en especial lo señalado en David CALDEvilla DomínGuEZ, "Las independencias americanas: historiografía, prensa e identidad criolla", en Historia y Comunicación Social, vol. 16, 2011, pp. 20-21 [pp. 13-31]). Entre otros, han sido renovadores los estudios de G. di Meglio, R. Fradkin y S. Mata (Argentina); J. Pinto Vallejos (Chile); A. Frega (Uruguay); L. León (Venezuela); E. van Young (México); M. L. Soux (Bolivia); y, en el caso peruano, la lúcida aproximación histórica de Cecilia MÉndez Gastelumend, The Plebeian Republic. The Huanta Rebellion and the Making of the Peruvian State: 1820-1850. DurhamLondres, Duke University Press, 2005, pp. 68-69.

22 Pablo Ortemberg, "La entrada de José de San Martín en Lima y la proclamación del 28 de julio: la negociación simbólica de la transición", Histórica, vol. 33, n. 2, 2009, pp. 65-108.

23 Bartolomé Mitre, Historia de San Martín y de la emancipación sudamericana. Buenos Aires, Imprenta de la Nación, 1888, p. 180.

24 El salmista pone en boca de Dios: "Encontré a David, mi servidor, y lo ungí con óleo santo" $($ Sal 89, 21). La elección confiere la potestad; la unción, la autoridad. Esta última, en términos teológicos, se identifica con la gracia de estado. 
República del Perú, que ha proyectado cierto carácter sagrado. ${ }^{25}$ Reputada por R. Vargas Ugarte como "la más verídica relación del suceso", ${ }^{26}$ la fuente primaria de esa declaración de la independencia es la recogida por la Gaceta del Gobierno de Lima Independiente, en su publicación del 1 de agosto de $1821 .^{27}$

Jorge Basadre inicia su monumental obra sobre la Historia de la República del Perú citando, precisamente, las palabras del general José de San Martín al proclamar la independencia del Perú aquel 28 de julio de 1821 en la Plaza de Armas de Lima. Según el insoslayable historiador tacneño, se trató de "una declaración con raíz y con alas", es decir, tuvo la virtud de volverse al pasado para, seguidamente, formular una promesa futura: la del imperio de la justicia y de la libertad en el Perú. Seguidamente, entre paréntesis, como si fuese una tímida digresión, Basadre comenta el sentido histórico de la invocación divina:

En sus solemnes palabras [San Martín] hace también una invocación a Dios, es decir, consagra creencias y principios precisamente sembrados por España, manteniendo el patrimonio cultural y espiritual representado no solo por el idioma, sino también por la religión cristiana. ${ }^{28}$

Cuando, en setiembre del mismo año de la proclamación de la independencia, San Martín informó a los habitantes de Lima, a través de una proclama, que las tropas del general La Serna se movían temerariamente desde San Mateo en dirección a la capital, con intención de retomarla y arrostrar el espíritu independentista, les aseguró también el auxilio incondicional de sus tropas para defenderlos de cualquier tipo de ataque. ${ }^{29}$ Se limitó a exigirles tres cosas: unión, tranquilidad y eficaz cooperación. Aunque, finalmente, se trató de una falsa alarma, la descripción de Sebastián Lorente que da cuenta de la respuesta de los limeños a la advertencia del Libertador señala con elocuencia

\footnotetext{
25 Con un agudo análisis, Natalia Sobrevilla Perea ha afirmado: "A diferencia de otros países de la región, lo que se conmemora en el Perú no son los 'documentos', sino los 'actos': la proclamación pública y el tedeum que se celebra en la Catedral cada 29 de julio en honor al que celebró San Martín el día después de la proclamación", cf. Entre proclamas, actas y una capitulación: La independencia peruana vista en sus actos de fundación, en Alfredo ÁviLA; Jordana Dym; Erika PANi [coords.], Las declaraciones de independencia. Los textos fundamentales de las independencias americanas. Ciudad de México, El Colegio de México-Universidad Nacional Autónoma de México, 2013, p. 241 [pp. 241-274]).

26 Rubén Vargas Ugarte, Historia general del Perú, t. VI: Emancipación (1816-1825). Lima, Editor Carlos Milla Batres [impreso en Barcelona por I. G. Seix Barral Hnos.], 1966, p. 176.

27 Ver nota 2.

28 Jorge Basadre Grohmann, Historia de la República del Perú, tomo I: 1822-1933. Lima, Editorial Universitaria, $1968^{6}$, p. 2.

29 Cf. José de San Martín, "Proclama del protector de la libertad del Perú a los habitantes de Lima", en Biblioteca de Mayo: colección de obras y documentos para la historia argentina, Vol. 17: Guerra de la independencia. Expedición libertadora al Perú, campañas a la sierra, proclamación y jura de la independencia del Perú, José de San Martín, protector de la libertad del Perú, Junín y Ayacucho, Fragata corsario La Argentina. Buenos Aires, Senado de la Nación, 1963, p. 74.
}

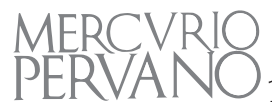


cómo el ideal independentista había sido abrazado por los diferentes sectores de la sociedad -mujeres y eclesiásticos incluidos- y cómo habían ido disponiéndose progresivamente los ánimos para defenderlo: ${ }^{30}$

El bello sexo, no contento con exhortar en secreto y perorar en grupos, se presentó con cuchillos y tijeras a falta de otras armas. Los mulatos organizaron un batallón para defender las murallas. Los eclesiásticos salieron a la calle, llevando crucifijos en una mano, y en la otra puñales [...]. La plaza mayor se hinchió de gente inflamada de ardor guerrero, formándose en línea de batalla los mulatos hacia el cabildo armados de cuchillos, y los clérigos y frailes al pie de las gradas de la catedral, con espadas en mano. Las señoras excitaban desde los balcones el mayor entusiasmo. ${ }^{31}$

\section{Aquel acto doble de la proclamación y la jura ${ }^{32}$ se convirtió en la línea}

30 Rosa María Martínez de Codes señala: “Entre 1814 y 1820, el espíritu de resistencia de los criollos pareció prácticamente extinguido y solo el desembarco del general San Martín al sur de Lima, modificó la situación". Ver La Iglesia católica en la América independiente (siglo XIX). Madrid, Editorial Mapfre, 1992, p. 106). Un recuento de Basilio Hall (1788-1844), comandante naval británico que lideró expediciones científicas y militares alrededor del mundo, da cuenta de la incertidumbre que todavía se vivía en Lima después de la proclamación de la independencia. Ver Basil Hall, "Lima in 1821", en Carlos Aguirre y Charles F. Walker [eds.], The Lima Reader. History, Culture, Politics. Durham-Londres, Duke University Press, 2017, pp. 69-72. Véase su testimonio sobre el asedio y la toma de la capital, la proclamación de la independencia y la instauración del protectorado, en Basil HaLl, El impacto de San Martín en el Perú. Lima, Roguimasalma Editores, 1998, pp. 46-86. La traducción al castellano del texto de Hall y otros viajeros se puede ver en Estuardo NúÑEz, El Perú visto por viajeros. Lima, Peisa, 2 vols. 1973-1974. El mismo autor amplía su trabajo en Viajes y viajeros extranjeros por el Perú. Apuntes documentales con algunos desarrollos histórico-biográficos. Lima, Concytec, 1989.

31 Sebastián Lorente, Historia del Perú desde la proclamación de la independencia, vol. I: 18211827. Lima, Imprenta Calle de Camaná, 1876, p. 25.

32 El sábado 28 de julio se realizó la proclamación en cuatro plazas principales de Lima y el domingo 29 de julio se inició la jura de la independencia. Es decir, proclamación y jura dejaron de ser sinónimos para ser dos actos formalmente autónomos. Es posible identificar algunas similitudes con la Constitución de Cádiz de 1812, que declaraba la necesidad de juramentar la defensa y conservación de la religión católica, apostólica y romana y, del mismo modo, guardar religiosamente la Constitución política de la monarquía española: la jura correspondería a los principales actores del gobierno: los diputados (art. 117), el rey (art. 131), la regencia (art. 196), el príncipe de Asturias (art. 212), los consejeros del Estado (art. 241), los magistrados y los jueces (art. 279), los individuos de los ayuntamientos y diputaciones (art. 337) y toda persona que ejerciere cargo público, civil, militar o eclesiástico (art. 374). Se ha hecho notar que el vector religioso permea de principio a fin el texto de la Constitución y, por consiguiente, la liturgia acompañaba también inseparablemente la vida política de la España de inicios del siglo XIX. Cf. Antonio Fernández, Las cortes y la Constitución de Cádiz. Madrid, 2010, p. 71. En el caso peruano, el acta de la jura de la independencia fue redactada y suscrita por la mayoría de los miembros del cabildo, el clero secular y notables de la sociedad ("personas de reconocida probidad, luces y patriotismo") el 15 de julio de 1821 en la Ciudad de los Reyes (Lima); el documento histórico de la declaración se encuentra custodiado por la Biblioteca y Archivo Histórico de Lima; véase el acta en Alfredo Ávila; Jordana Dym; Erika PANi [coords.], Las declaraciones de independencia. Los 
divisoria entre aquellos que se adscribían a la declaración de la independencia y aquellos que se resistían a acatar las leyes relativas a ella, emanadas desde el Protectorado de San Martín. Los realistas fueron quienes pagaron la factura más cara por haber permanecido leales al sistema español. Para estos, las consecuencias fueron proporcionales a la virulencia de la guerra civil: desde el embargo de sus bienes hasta su confinamiento y expulsión del país. ${ }^{33} \mathrm{~A}$ fines de 1821, San Martín ordenó que los españoles que no hubieran obtenido una "carta de naturaleza", debían abandonar el país, puesto que, en la república peruana en ciernes, el hecho de no ser ciudadano merecía la privación del cargo ejercido a la fecha, a todo nivel: eclesiástico, civil o militar. ${ }^{34}$

Es interesante notar que, no obstante el ensañamiento legislativo y ejecutivo que se hubiese descargado en contra de los españoles, no sucedió lo mismo en contra de la religión. No hubo, pues, una identificación entre el 'enemigo europeo' y la religión que este había traído consigo y logrado instaurar durante los tres siglos de dominación. Se logró diferenciar oportunamente ambos aspectos, porque se pudo interiorizar previamente el credo legado y, consiguientemente, hubo una apropiación de él: la religión católica informó también la identidad del americano y coadyuvó a que este concibiera una legítima noción de patria. ${ }^{35}$ No extraña, entonces, que San Martín hubiese asumido como un deber inherente a su condición de Protector del Perú la defensa, el mantenimiento y

textos fundamentales de las independencias americanas, Ciudad de México, El Colegio de MéxicoUniversidad Nacional Autónoma de México, 2013, pp. 537-538.

33 Cf. José de SAN Martín, “Decreto nombrando una junta de secuestros, y mandando que se embarguen los bienes de los emigrados [Cuartel General de la Legua, 18 de julio de 1821]", en Colección de leyes y decretos sancionados desde la jura de la independencia, t. 1, Lima, Imprenta del Estado por J. Gonzales, 1825, pp. 6-7.

34 Cf. Ascensión Martínez RiazA, "El peso de la ley: la política hacia los españoles en la independencia del Perú (1820-1826)", Procesos: Revista Ecuatoriana de Historia, n. ${ }^{\circ} 42,2015$, p. 83 [pp. 65-97].

35 Cf. José Gabriel Brauchy, La ambigua independencia americana: ruptura y continuidad [dissertation for the degree of Doctor of Philosophy-Department of Spanish and Portoguese]. Nueva York, 2004, p. 186. En su carta dirigida a Francisco Paula Otero, Isidoro Villar se refiere a algunos miembros del clero que apoyaban al bando realista en los siguientes términos: “Usted como Presidente del Departamento debe hacer presente al Gobierno así eclesiástico como político que de ninguna manera debía estar en ese curato Burgos, porque ya debe saber usted que los pueblos de la quebrada están más propensos al sistema real que a nuestra Independencia y aunque no sea más que por este motivo no deben haber curas tan insolentes y déspotas como este, que a todos nos trata de cholos, y sobre todo si Cataño es malo, vuelvo a decir este es pésimo", citado en Héctor Huerto Vizcarra [ed.], Nueva Colección Documental de la Independencia del Perú, Vol. 3: Guerrillas y montoneras durante la independencia, Lima, Acuedi, 2018, p. 124. Saludamos el proyecto en marcha de la edición digital de la Colección Documental de la Historia del Perú, en un esfuerzo conjunto de la Universidad Peruana de Ciencias Aplicadas, el Fondo Editorial del Congreso del Perú, la Asociación por la Cultura y la Educación Digital, la Fundación M. J. Bustamante de la Fuente y la Red de Investigadores Indigenistas.

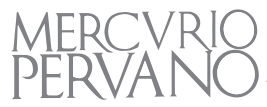


la conservación de la religión católica, y castigar a quienes la contravinieren. ${ }^{36}$ En este sentido, Martínez Albesa ha hecho notar cómo el reconocimiento del aporte singular de la Iglesia católica a la forja nacional y el respeto firme por la libertad religiosa han "animado la evolución histórica de las relaciones entre el Estado y la Iglesia del Perú" ${ }^{37}$ En efecto, ya desde los primeros años de la nación peruana, tal relación se vio vinculada concretamente a través de la legislación. La Constitución de 1823 refleja bien esta identificación entre el credo religioso y el ideario republicano. ${ }^{38}$ Así, en los dos artículos que conforman el tercer capítulo se establecía categóricamente que "la religión de la República es Católica, Apostólica, Romana, con exclusión del ejercicio de cualquier otra" (art. 8); y que "es un deber de la Nación protegerla constantemente, por todos los medios conformes al espíritu del Evangelio, y de cualquier habitante del Estado respetarla inviolablemente" (art. 9). ${ }^{39}$

San Martín, a través de su discurso, intentó inclinar la voluntad divina hacia "la justicia de la causa" del Perú que el Dios Católico, Apostólico y Romano debía defender. Si aquel acto oficial no fue sino un 'valioso prisma' capaz de "develar los actos y los pactos que estuvieron en juego en los umbrales del Perú republicano", ${ }^{40}$ entonces el discurso de San Martín constituyó el introito de esa liturgia republicana, en la que él mismo se entronizó en la cátedra que había dejado vacante el último virrey del Perú. No obstante, el oficio litúrgico no acabó al día siguiente con el tedeum; este se prolongaría durante largos años. El amén final -el Deo gratias- se haría esperar.

36 De la Puente Candamo habla de la obligatoriedad de la profesión de la "religión del Estado" como requisito para el desempeño de cualquier función pública. Su estudio [tesis doctoral de Historia en la Pontificia Universidad Católica del Perú] sirve también para analizar la perspectiva de los historiadores peruanos en la primera mitad del siglo XX sobre la actitud del protector del Perú respecto a la religión. Cf. José Agustín de la Puente Candamo, San Martín y el Perú. Planteamiento doctrinario. Lima, Editorial Lumen, 1948, pp. 177-180.

37 Emilio Martínez Albesa, La separación entre el Estado y las confesiones religiosas: ¿límite o potencialidad para la realidad religiosa? Los casos diversos, originales y elocuentes de México y Perú, Ecclesia, XXX, n. ${ }^{\circ} 1,2016$, p. 98 [pp. 83-108].

38 La Constitución Política de la República del Perú de 1823 fue elaborada por el Primer Congreso Constituyente del Perú, instalado en 1822; y promulgada por el presidente José Bernardo de Tagle (IV Marqués de Torre Tagle y segundo presidente del Perú, que sucedió a José de la Riva Agüero) el 12 de noviembre de 1823.

39 La Constitución de 1823 entraría en vigencia después del periodo de guerras por la independencia, después de la caída del régimen vitalicio y regiría desde inicios de 1827 hasta la promulgación de la nueva Constitución en 1828, la cual, en materia religiosa, se mantuvo esencialmente invariable. En 1874, a través de la bula "Preclara inter beneficia", el papa Pío IX otorgó el derecho del patronato a los presidentes en función de la República del Perú que profesaran la fe católica. Cf. Carlos Salinas Araneda, “Los concordatos celebrados entre la Santa Sede y los países latinoamericanos durante el siglo XIX", en Revista de Estudios HistóricoJurídicos [Sección Historia del Derecho Canónico], XXXV, 2013, pp. 249-250 [pp. 215-254].

40 Ver Pablo Ortemberg, La entrada..., p. 108. 